\title{
OPTIMALISASI PENGAWASAN BUNKER BAHAN BAKAR KAPAL TNI-AL UNTUK MENGURANGI TERJADINYA OIL SPIL DI DERMAGA KOARMADA OLEH PT. PERTAMINA TRANS KONTINENTAL CABANG SURABAYA
}

\author{
Jevri Eko Satria ${ }^{a}$, Andy Wahyu Hermanto ${ }^{b}$ \\ ${ }^{a}$ Taruna Prodi KALK Politeknik Ilmu Pelayaran Semarang, \\ ${ }^{b}$ Dosen Prodi Studi Ketatalaksanaan Angkutan Laut dan Kepelabuhanan \\ Politeknik Ilmu Pelayaran Semarang.
}

\begin{abstract}
ABSTRAK
Kegiatan pengisian bahan bakar (bunker) merupakan sebuah kegiatan pengisian bahan bakar yang di lakukan rutin sebelum kapal siap berlayar, akan tetapi seiring berjalannya waktu kegiatan bunker juga membawa permasalahan baru seperti kejadian oil spill yang terjadi di dermaga koarmada. Potensi terjadinya permasalahan yang menyebabkan oil spill sangatlah tinggi. Adapun tujuan dari penelitian ini adalah 1). Untuk mengetahui kegiatan pengawasan bunker di dermaga Koarmada, 2). Mengetahui faktorfaktor yang menyebabkan terjadinya oil spill serta 3). Upaya yang di lakukann PT. Pertamina Trans Kontinental cabang Surabaya untuk mengurangi terjadinya oil spill. Metode penelitian yang di gunakan adalah 1). Deskriptif kualitatif dengan mendeskripsikan secara terperinci pelaksanaan pengawasan bunker di dermaga Koarmada. Pengumpulan data dilakukan dengan wawancara, observasi, studi pustaka dan dokumentasi berupa fotofoto pelaksanaan pengawasan bunker. Dari hasil penelitian dapat di ketahui bahwa 1). Kegiatan pengawasan di dermaga Koarmada masih belum optimal. 2). Faktor faktor yang menyebabkan oil spill antara lain faktor pendidikan, faktor pengetahuan, dan faktor peralatan yang sudah tidak layak. Berdasarkan hasil penelitian sebaiknya PT. Pertamina Trans Kontinental melakukan 3). Upaya untuk mengurangi terjadinya oil spill dengan lebih memperhatikan latar belakang pendidikan dalam merekrut pekerja bunker, memberikan pelatihan dan sosialisasi kepada tim pengawas, memberikan sanksi yang tegas kepada pekerja bunker jika bunker dilaksanakan tidak sesuai dengan prosedur, memperbarui peralatan bunker yang sudah tidak layak pakai, lakukan pengawasan secara menyeluruh, serta lakukan komunikasi dan koordinasi dan kerjasama yang baik di dalam pengawasan aktifitas bunker.
\end{abstract}

Kata kunci: Pengawasan, Bunker, Oil spil.

\section{PENDAHULUAN}

Bahan bakar minyak adalah salah satu unsur vital yang diperlukan dalam pelayanan kebutuhan masyarakat umum baik di negara-negara miskin negaranegara berkembang maupun di negaranegara yang telah berstatus negara maju sekalipun, bahan bakar minyak merupakan suatu jenis bahan bakar yang dihasilkan melalui proses pengilangan minyak mentah, saat ini bahan bakar minyak telah menjadi kebutuhan pokok dalam kegiatan rumah tangga maupun industri, terlebih dalam kegiatan transportasi. Seiring dengan meningkatnya penggunaan kendaraan sebagai media transportasi baik umum maupun pribadi, menyebabkan kebutuhan Bahan bakar minyak juga meningkat. Hal tersebut dikarenakan Bahan bakar minyak merupakan sumber energi yang diperlukan untuk dapat 
menggerakkan mesin kendaraan sehingga bisa berjalan sebagaimana mestinya.

Dalam istilah pelayaran kegiatan pengisian bahan bakar kapal dikenal dengan nama bunker, bunker merupakan sebuah kegiatan pengisian bahan bakar yang dilakukan rutin sebelum kapal siap berlayar, akan tetapi seiring berjalan nya waktu ternyata kegiatan bunker juga membawa permasalahan baru.

Setelah pengoperasian bunker bahan bakar ternyata fenomena pencemaran minyak mulai muncul. Maka di butuhkan peraturan-peraturan yang mengatur pencegahan dan pembatasan halhal yang berkaitan dengan tumpahan minyak.

Setelah terbentuk International Maritime Organization (IMO) dalam badan United Nation (PBB) pada tahun 1998, usaha membuat peraturan-peraturan itu muncul tetapi masih ditentang banyak pihak. Tahun 1959 di Inggris lahir "oil pollution convention" untuk mencegah pembuangan campuran minyak dari pengoperasian kapal tanker dan kamar mesin kapal lainnya, diamandemen tahun 1962 dan 1969. Jadi, sebelum tahun 1970 pengaturan permasalahan "marine pollution" baru pada tingkat prosedur pengoperasian.

Baru kemudian kita disadarkan tentang pentingnya memikirkan bersama pencegahan pencemaran, dengan adanya pencemaran besar SS.Torey Cayon tahun 1967 setelah diadakan sidang "International Conference on Marine Pollution" dan lahirlah "International Conference for the Prevention of oil pollution from ship's" (dikenal dengan MARPOL) tahun 1973 dan disempurnakan dengan Tanker Safety and Pollution Prevention (TSPP) dan dikenal dengan Marpol 1973/1974, yang sampai saat ini masih menjadi peraturan terbesar dibidangnya.

Dikarenakan jumlah kegiatan bunker dari waktu ke waktu semakin bertambah maka otomatis tingkat pencemaran akan meningkat baik minyak yang tertumpah tersebut dalam jumlah besar maupun sedikit, sehingga dalam berlangsungnya kegiatan operasional bunker bahan bakar kapal harus di awasi dengan baik untuk mengurangi terjadinya kecelakaan kecelakaan yang dapat mengakibatkan pencemaran. Selama melaksanakan praktek darat, peneliti menemukan adanya permasalahan yang terjadi pada tanggal 26 Juni 2018. Kejadian terjadi di saat pengisian bahan bakar kapal yang seharusnya menggunakan SPOB (self propeller oil barge) dialihkan menggunakan mesin pompa diesel air karena pompa mesin SPOB mengalami trouble.

Dimana kegiatan bunker dengan menggunakan mesin diesel tidak sesuai dengan prosedur dan juga selang yang di gunakan sudah tidak layak pakai, sehingga dalam kegiatannya terjadi tumpahan minyak yang di sebabkan oleh lepasnya selang dari pipa hose mesin diesel. Hal ini terjadi karena kurang maksimalnya tim pengawas dalam mengawasi kegiatan bunker, dimana tim pengawas mengizinkan para awak kapal untuk bunker dengan menggunakan mesin diesel pompa air. Maka dari itu dalam kegiatan bunker di dermaga Koarmada harus perlu adanya pengawasan yang lebih mendalam untuk mengurangi terjadinya kecelakaan yang menyebabkan oil spill.

Atas dasar permasalahan di atas, maka penulis ingin mengangkat fenomena tersebut ke dalam sebuah penelitian yang berjudul "Pentingnya Pengawasan Bunker Bahan Bakar Kapal TNI-AL Untuk Mengurangi Terjadinya Oil Spill Di Dermaga Koarmada Oleh PT. Pertamina Trans Kontinental Cabang Surabaya”.

\section{METODE PENELITIAN}

Metode yang penulis gunakan dalam penelitian ini adalah deskriptif dan kualitatif. Penelitian ini ditulis secara deskriptif, yang mana berisi uraian atau 
penjabaran beberapa teori dan menghubungkan variabel satu dengan variabel yang lain. Analisis yang digunakan dalam penelitian kualitatif lebih bersifat deskriptif analitik yang berarti interpretasi terhadap isi yang dibuat dan disusun secara sitematik dan menyeluruh dimana penelitian ini mendapat informasi dari sumber-sumber orang yang bersangkutan. Yaitu mealalui lisan ataupun catatan yang ditulis oleh narasumber.

Penulis menjabarkan hasil pembahasan dengan memberikan solusi secara sistematik dan logis berdasarkan fakta-fakta pada oyek yang diteliti. Penulis berusaha memberikan gambaran tentang bagaimana sitem kerja PT. Pertamina Trans Kontinental dan faktor-faktor penyebab terjadinya oil spill saat kegiatan bunker bahan bakar berlangsung.

\section{HASIL DAN DISKUSI}

\section{A. Hasil}

Pembahasan hasil difokuskan kepada permasalahan yang dikaji.

\section{Bagaimana proses kegiatan pengawasan bunker bahan bakar di dermaga koarmada. \\ Menurut George R. Terry} (2011: 110) "Pengawasan dapat dirumuskan sebagai proses penentuan apa yang harus dicapai yaitu standard, apa yang sedang dilakukan yaitu pelaksanaan, menilai pelaksanaan, dan bila mana perlu melakukan perbaikanperbaikan, sehingga pelaksanaan sesuai dengan rencana, yaitu selaras dengan standard (ukuran). Dari hasil observasi yang dilakukan proses kegiatan pengawasan bunker bahan bakar di dermaga Koarmada masih belum optimal dikarenakan tim pengawas sendiri sebagian besar berasal dari pihak TNI AL, dimana dalam melaksanakan pengawasan bunker yang baik dan benar masih kurang maksimal. Dalam kegiatan bunker di dermaga koarmada marine surveyor ikut berperan sebagai pengawas. Dengan adanya marine surveyor yang ditunjuk oleh PT.Pertamina Trans Kontinental untuk menjadi pihak penengah antara pihak kapal tug boat tongkang sebagai pengisi bahan bakar dan kapal KRI Kapal Republik Indonesia) sebagai penerima, akan tetapi dengan adanya marine surveyor menjadikan tim pengawas bunker yang berasal dari pihak TNI masih bergantung dengan semua keputusan marine surveyor. Dengan ini tim pengawas yang berasal dari pihak TNI harus dibekali pengetahuan khusus untuk menunjang kegiatan bunker supaya dalam mengawasi bunker dapat lebih maksimal.

2. Faktor apa saja yang menyebabkan terjadinya oil spill pada saat kegiatan operasional bunker di dermaga Koarmada

Dari hasil wawancara dengan salah satu awak kapal tongkang bintang, Jefri pada intinya dijelaskan bahwa tidak optimalnya pelaksanan bunker dikarenakan dari para pengawas belum mematuhi prosedur kerja yang telah dibuat, di samping tidak hanya dari segi pengawas sendiri, tapi dari segi awak kapal dan alat penunjang pekerjaan itu sendiri, seperti awak kapal terlalu berani mengambil resiko saat pompa bunker spob trouble sehingga bunker tetap dilaksanakan akan tetapi menggunakan alat pompa air yang di mana itu sangat beresiko dan dapat memicu terjadinya oil spill serta tidak diperbaruinya alat alat penunjang kegiatan bunker yang sudah tidak layak pakai pada saat proses kegiatan bunker di dermaga Koarmada yang tentunya dapat menghambat pekerjaan jika terjadi oil spill.

3. Upaya yang di lakukan untuk mengurangi terjadinya oil spill pada saat kegiatan operasional bunker.

Upaya dalam peranan untuk mengurangi terjadinya oil spill sebelum 
melaksanakan kegiatan bunker bahan bakar di dermaga Koarmada yaitu:

a. Melakukan pengecekan secara menyeluruh untuk memastikan bahwa kapal memang benar benar siap untuk melaksanakan kegiatan bunker.

b. Melakukan safety meeting sebelum melaksanakan proses bunker.

c. Melakukan pelatihan terhadap para pengawas tentang bagaimana mengawasi kegiatan bunker yang baik dan benar sesuai prosedur yang berlaku.

d. Memberikan sanksi yang tegas terhadap awak kapal yang melakukan bunker tidak sesuai prosedur.

\section{B. Pembahasan Masalah}

\section{Bagaimana proses kegiatan pengawasan bahan bakar di deramaga koarmada?}

Dalam proses kegiatan bunker bahan bakar di dermaga koarmada terdapat tim pengawas yang harus mengawasi jalannya kegiatan operasional bunker, pengawas tersebut terdiri dari:

a. Pengawas dari pihak TNI

Berikut daftar tim pengawas yang berasal dari pihak TNI:

1) Kepala tim

2) Staff intelejen

3) Staff logistik

4) Dinas material dan pembekalan

5) Polisi militer

6) Polisi militer angkatan laut

b. Serveyor

c. PT. Pertamina Trans Kontinental

d. Pihak penerima bunker (pihak kapal) Pada saat kegiatan bunker bahan bakar kapal di dermaga Koarmada peran tim pengawas sangatlah penting maka dari itu pihak PT. Pertamina Trans Kontinental menunjuk perusahaan PT. Surveyor Indonesia sebagai jasa marine survey dalam membantu proses kegiatan pengawasan bunker dan untuk menghindari terjadinya kecurangan, kekurangan atau kesalah pahaman dalam kegiatan pengisian bahan bakar kapal.

Berikut prosedur yang seharusnya dilakukan saat melaksanakan kegiatan bunker bahan bakar kapal adalah:

a. Pertama setelah kita sampai di kapal langsung menemui perwira kapal, Kapten kapal ataupun Chief engineer bahwa akan dilaksanakannya kegiatan bunker.

b. Memeriksa dan memastikan alat ukur tabel yang digunakan dapat di pastikan sudah dengan baik dan masih valid.

c. Pastikan crew kapal tidak melakukan aktifitas yang dapat mengganggu proses pada saat pengukuran/sounding.

d. Melakukan pengukuran sounding sebelum proses bunker atau transfer bahan bakar dimulai. Catat semua data sounding awal dan kegiatan ini harus disaksikan oleh seluruh tim pengawas, perwakilan kapal, atau pihak antara suplier dan receiver.

e. Jika diperlukan memasang segel atau seal pada manifold, tanki, pompa, kran-kran, atau line yang tidak digunakan untuk menghindari kecurangan pada aliran minyak.

f. Catat angka flow meter awal sebelum start dimulai.

g. Setelah itu dapat dilakukan transfer minyak/bunker. Pada saat proses bunker surveyor dan tim pengawas wajib tetap memonitor kegiatan dengan memperhatikan flowmeter reading, selang hose yang digunakan, rate pompa, memperhatikan hal-hal mencurigakan pada crew kapal untuk menghindari penyalahgunaan ataupun pencurian minyak, serta memastikan minyak hanya mengalir menuju tanki nominasi kapal reciver. 
h. Setelah pengisian bunker selesai atau sudah sesuai dengan DO atau rencana bunker, lakukan pengukuran lagi atau bisa disebut sounding akhir.

i. Setelah stop pompa jangan lupa untuk mencatat flow meter akhir.

j. Melakukan perhitungan dari hasil sounding awal dan sounding akhir untuk menentukan jumlah bunker dengan tetap memperhitungkan nilai-nilai koreksi baik dari trim, list, koreksi temperature, dan density untuk menentukan volume MT.

k. Jika kedua belah pihak antara pihak tongkang dan pihak kapal yang di isi maka kegiatan bunker bisa dinyatakan deal atau telah selesai tanpa adanya masalah di kemudian hari.

Selama penulis melaksanakan kegiatan bunker ada beberapa hal yang ditemukan oleh penulis di lapangan, yaitu:

a. Surveyor dalam melaksanakan pekerjaannya sering terlambat.

b. Lemahnya pengawasan dari pihak tim pengawas TNI.

c. Kurang maksimalnya tim pengawas dalam mengawasi kegiatan operasional bunker.

d. Pihak awak kapal yang kurang mengutamakan keselamatan dalam bekerja.

e. Pihak awak kapal, TNI, dan pengawas tidak memakai alat pelindung diri.

2. Faktor apa saja yang menyebabkan terjadinya oil spill pada saat kegiatan operasional bunker PT. Pertamina Trans Kontinental ?

a. Kurang maksimalnya tim pengawas dalam mengawasi bunker.

Dalam mengawasi kegiatan bunker tim pengawas seringkali lalai dalam melaksanakan pekerjaannya, bahkan dalam melaksanakan pengawasan bunker tim pengawas sampai ada yang tertidur.

b. Bunker yang tidak sesuai SOP (Standard Operational Procedure).
Kegiatan bunker yang tidak sesuai dengan SOP menjadi faktor penyebab terjadinya oil spill yang dimana awak kapal menggunakan alat bunker alternatif lain disaat bunker dengan menggunakan spob tiba tiba trouble, tentunya ini sangat berbahaya bila diterapkan saat kegiatan bunker. Seperti dengan menggunakannya pompa diesel sebagai alat bunker alternatif pengganti spob yang sedang trouble.

c. Tidak diperbaruinya alat pendukung logistik bunker yang sudah tidak layak pakai.

Tidak diperbaruinya alat pendukung logistik bunker juga menjadi faktor yang dapat memicu terjadinya oil spill. Seperti selang atau pipa bunker yang sudah tidak layak tetapi masih tetap saja di gunakan.

3. Upaya apa yang dilakukan untuk mengurangi terjadinya oil spill pada saat kegiatan operasional bunker PT. Pertamina Trans Kontinental ?

Upaya yang harus dilakukan untuk mengurangi terjadinya oil spill pada saat kegiatan operasional bunker bahan bakar di dermaga Koarmada, berikut langkah yang harus diambil adalah:

a. Memberikan pelatihan kepada tim pengawas bunker dan sosialisasi tentang kegiatan bunker yang baik dan sesuai dengan prosedur.

Yang dimaksudkan dalam hal ini adalah selaku badan usaha yang menaungi tenaga kerja bunker di pelabuhan Koarmada Timur Surabaya memfasilitasi tim pengawas bunker untuk menyelenggarakan seminar mengenai pengawasan bunker bahan bakar yang efektif dengan mengundang narasumber yang ahli di bidangnya. Seminar ini di maksudkan agar tenaga kerja pengawas mengerti kaidah-kaidah 
dalam mengawasi kegiatan bunker sesuai prosedur yang telah di buat.

b. Memberikan sanksi terhadap awak kapal jika tidak melaksanakan kegiatan bunker sesuai dengan prosedur yang telah ditetapkan dengan tujuan untuk mendisiplinkan para pekerja.

Setiap karyawan akan berprestasi, mencetak kinerja yang maksimal apabila bekerja dengan disiplin penuh, bukan saja karena harus diawasi dan diatur setiap hari tetapi karena tuntutan keberhasilan itu adalah disiplin pada dirinya sendiri. Apabila kesadaran ini semakin tinggi dimiliki oleh setiap karyawan, maka peluang keberhasilan pekerjaannya akan sangat tinggi. Sesungguhnya disiplin itu sebagai pembelajaran bagi setiap pekerja yang mendorong pengendalian diri, dedikasi, dan perilaku tertib saat bekerja. Dalam sebuah perusahaan, disiplin umumnya digunakan dalam arti terbatas yang berarti sanksi atau hukuman. Dalam hal ini penerapan sikap disiplin digunakan untuk menertibkan sikap semua pekerja bunker yang melakukan pekerjaan tidak sesuai dengan prosedur di sertai dengan sanksi dan tindakan nyata agar para pekerja bunker lebih mematuhi prosedur kerja yang telah di buat.

c. Memperbarui fasilitas dan peralatan bunker yang sudah tidak layak pakai.

Yang dimaksudkan dalam hal adalah bila mana terdapat peralatan bunker yang sudah tidak layak pakai maka lebih baiknya untuk di ganti, diperbaiki atau di perbarui, dengan maksud dan tujuan untuk menghindari kejadian oil spill seperti di pembahasan faktor permasalahan yang menyebabkan terjadinya oil spill dikarenakan bocor nya pipa bunker yang sudah tidak layak untuk di pakai.

d. Melakukan pengawasan (controlling) secara menyeluruh. Yang dimaksudkan dalam hal ini adalah tim pengawas bunker wajib melakukan pengawasan di setiap kegiatan bunker, mulai dari sebelum di mulainya kegiatan bunker, saat bunker berlangsung, hingga selesainya kegiatan bunker. Hal ini bertujuan untuk meminimalisir terjadinya kecelakaan kerja, kecurangan dan kekurangan saat proses pengisian bahan bakar berlangsung. Maka di wajibkan untuk para pengawas supaya tidak lengah dalam melakukan pengawasan.

e. Melakukan komunikasi dan koordinasi yang baik dalam pengawasan aktifitas bunker dengan pihak terkait.

Yang dimaksud dalam hal ini adalah antara pihak awak kapal, pihak pengawas, pihak surveyor dan pihak kapal penerima harus menjalin hubungan komunikasi dan koordinyasi dengan baik dalam kegiatan pengawasan bunker bahan bakar, agar pelanggaran terhadap prosedur pengisian bunker dapat diminimalisir serta kecelakaan kerja dapat di hindari.

\section{SIMPULAN}

Berdasarkan hasil penelitian tentang masalah oil spill dalam kegiatan bunker di PT. Pertamina Trans Kontinental yang dituangkan dalam penulisan ini, maka penulis dapat menarik kesimpulan, antara lain:

1. Penyebab kurang optimalnya pengawasan bunker di dermaga Koarmada dikarenakan tim pengawas dalam melaksanakan pengawasan masih kurang maksimal, di samping itu tim 
pengawas dalam mengawasi kegiatan bunker seringkali lengah atau lalai bahkan ada yang sampai tertidur.

2. Faktor penyebab terjadinya oil spill di saat kegiatan operasional bunker di dermaga Koarmada adalah:

a. Pengawasan bunker yang kurang maksimal.

b. Tata cara Bunker yang tidak sesuai prosedur.

c. Tidak diperbaruinya alat pendukung logistik bunker yang sudah tidak layak pakai.

3. Upaya yang dilakukan untuk mengurangi ataupun mencegah terjadinya oil spill saat kegiatan operasional bunker di dermaga Koarmada yaitu:

a. Memberikan pelatihan kepada tim pengawas bunker dan sosialisasi tentang kegiatan bunker yang baik sesuai dengan prosedur.

b. Memperbarui fasilitas dan peralatan bunker yang sudah tidak layak pakai.

c. Melakukan pengawasan (controlling) secara menyeluruh.

d. Melakukan komunikasi dan koordinasi yang baik dalam pengawasan aktifitas bunker dengan pihak terkait.

Berdasarkan hasil penelitian tentang masalah oil spill dalam kegiatan bunker di PT. Pertamina Trans Kontinental yang dituangkan dalam penulisan ini, maka penulis dapat menarik kesimpulan, antara lain:

1. Penyebab kurang optimalnya pengawasan bunker di dermaga Koarmada dikarenakan tim pengawas dalam melaksanakan pengawasan masih kurang maksimal, di samping itu tim pengawas dalam mengawasi kegiatan bunker seringkali lengah atau lalai bahkan ada yang sampai tertidur.

2. Faktor penyebab terjadinya oil spill di saat kegiatan operasional bunker di dermaga Koarmada adalah:

a. Pengawasan bunker yang kurang maksimal. b. Tata cara Bunker yang tidak sesuai prosedur.

c. Tidak di perbaruinya alat pendukung logistik bunker yang sudah tidak layak pakai.

3. Upaya yang dilakukan untuk mengurangi ataupun mencegah terjadinya oil spill saat kegiatan operasional bunker di dermaga Koarmada yaitu:

a. Memberikan pelatihan kepada tim pengawas bunker dan sosialisasi tentang kegiatan bunker yang baik sesuai dengan prosedur.

b. Memperbarui fasilitas dan peralatan bunker yang sudah tidak layak pakai.

c. Melakukan pengawasan (controlling) secara menyeluruh.

d. Melakukan komunikasi dan koordinasi yang baik dalam pengawasan aktifitas bunker dengan pihak terkait.

\section{DAFTAR PUSTAKA}

Bungin, Burhan. 2015. Penelitian Kualitatif, Cetakan ke-8. Jakarta: PT. Kencana Prenada Media.

Hartanto, Beni. 2014. Oil Spill (Tumpahan Minyak) di Laut dan Beberapa kasus di Indonesia. Jogjakarta: PT. Bahari Jogja.

(http://zonainfosemua.blogspot.com/2011/ 01/pengertian-metode-penelitiankualitatif.html)

Kluijven, P.C. Van. 2015. Bunkering At Sea. London: Kluwer.

Lexy J, M. 2017. Metodologi Penelitian Kualitatif. Bandung: PT Remaja Rosdakarya.

Siswandi, Imam. 2014. Manajemen Perusahaan analisis dan pemecahannya. Bogor: Mitra Wacana Media. 
Optimalisasi Pengawasan Bunker Bahan Bakar Kapal TNI-AL Untuk Mengurangi Terjadinya Oil Spill Di Dermaga Koarmada Oleh PT. Pertamina Trans Kontinental Cabang Surabaya Jevri Eko Satria ${ }^{a}$, Andy Wahyu Hermanto ${ }^{b}$

Sondang P, Saigan. 2014. Sistem Informasi Manajemen. Jakarta: Bumi Aksara.

Sugiyono. 2017. Metodologi Penelitian Kuantitatif Kualitatif dan $R \& D$. Bandung: PT. Alfabeta.

Sujamto. 2014. Otonomi Daerah Yang Nyata dan Bertanggungjawab. Jakarta: Sinar Grafika. 